DEUTSCHE LANDE / DEUTSCHE KUNST

HERAUSGEGEBEN VON BURKHARD MEIER 


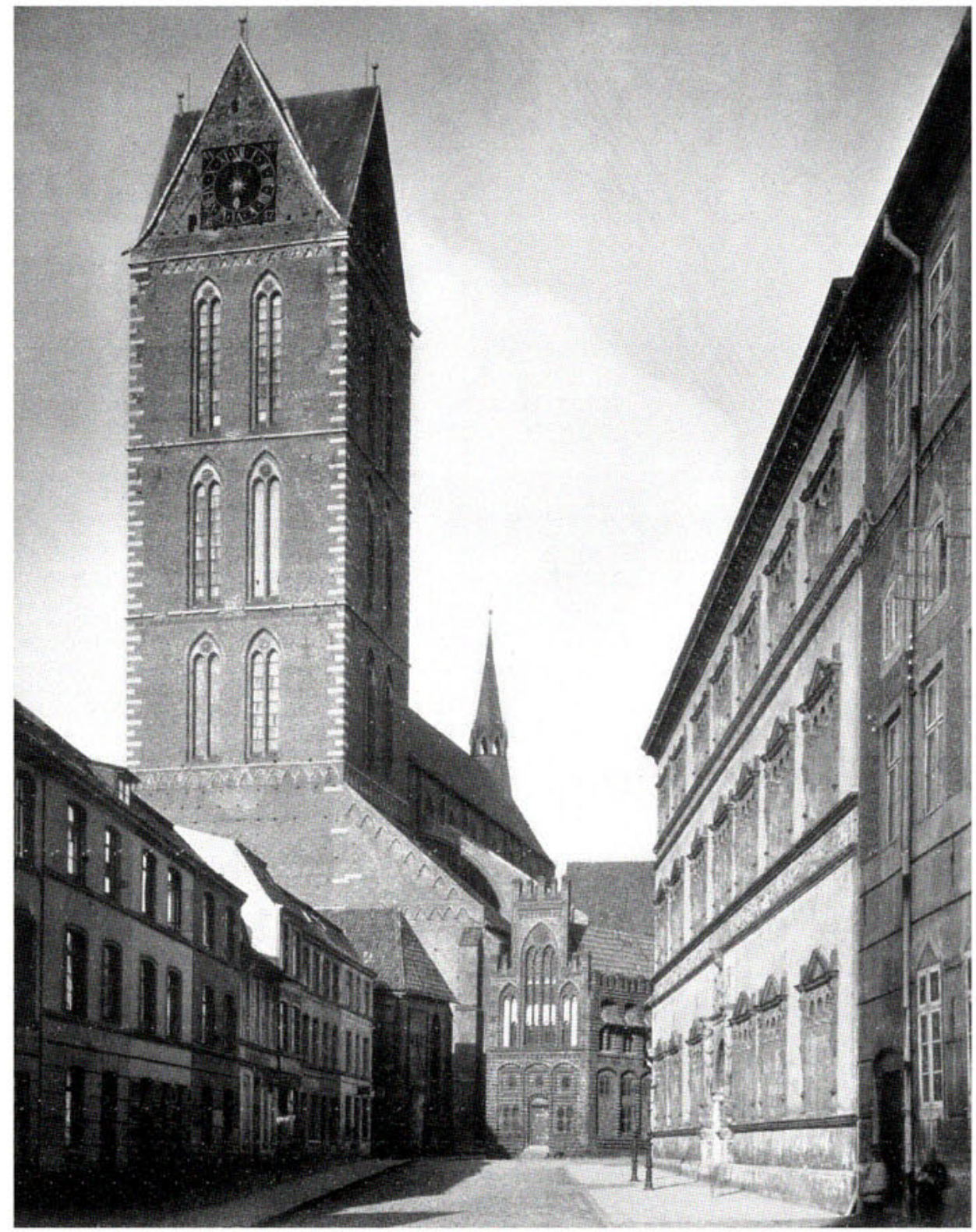

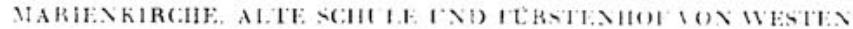




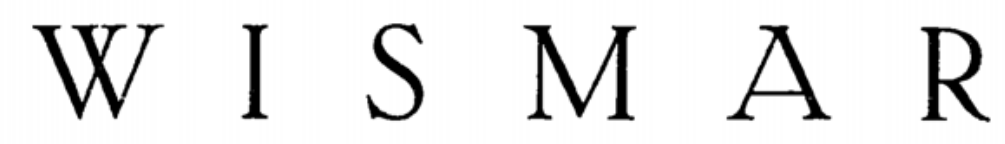

A UFGENOMMEN VON DER

STAATLICHEN BILDSTELLE

B ESCHRIEBEN VON

WER NER BURMEISTER

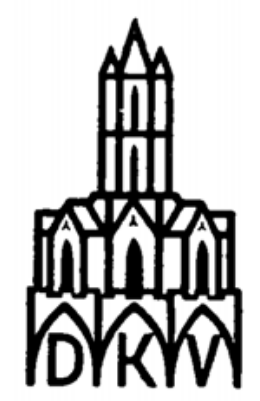

DEUTSCHER KUNSTVERLAG

B ERLI N / 1926 


\section{Es lieferten:}

Das Papier: Scheufelen in Oberlenningen / Die Drudkstödke: Angerer u.Gōldhl in Wien / Den Drưk: A.Wohlfeid,Magdeburg. Den Einband: G. Scäfer in Magdeburg / Den Entwurf zum Umsclag: Professor Ernst Böhm in Berlin / Das Wappen auf dem Einband: Werner Burmeister.

\section{Die Aufnahmen}

von Wismar, aus denen die 47 Tafeln dieses Buches nur eine kleine Auswahl bringen, sind in den Jahren 1923 und 1924 unter Leitung des Regierungsrats Theodor von Lūpke und des Verfassers durch den Photographen der Staatlicien Bildstelle Otto Hagemann gemaht worden. 